\title{
Using Zoom Webinar to Teach Advanced Topics in Crystallography
}

\author{
Joseph D. Ferrara ${ }^{1}$, Simon Bates ${ }^{1}$, Amanda Cochran ${ }^{1}$, Mark Del Campo ${ }^{1}$, Christian R. Göb ${ }^{2}$, Florian Kleemiß ${ }^{3}$, \\ Pierre Le Maguerès $^{1}$, Jeff Lengyel ${ }^{4}$, Mathias Meyer ${ }^{5}$, Horst Puschmann ${ }^{6}$, Keisuke Saito ${ }^{1}$, Christian Schürmann ${ }^{2}$, \\ Alexandra Stanley ${ }^{2}$, Paul N. Swepston ${ }^{1}$, Fraser White ${ }^{2}$, Jakub Wojciechowski ${ }^{2}$ \\ ${ }^{I}$ Rigaku Americas Corp., The Woodlands, TX, USA; \\ ${ }^{2}$ Rigaku Europe SE, Frankfurt, Germany; \\ ${ }^{3}$ University of Regensburg, Regensburg, Germany; \\ ${ }^{4}$ Cambridge Crystallographic Data Centre Inc, Boston, MA, USA; \\ ${ }^{5}$ Rigaku Polska Sp. z o. o., Wrocław, Poland; \\ ${ }^{6}$ OlexSys Ltd, Durham, United Kingdom;

\section{joseph.ferrara@rigaku.com}

In order to address the loss of crystallographic training opportunities resulting from the cancellation of conventional schools around the world due to the COVID-19 pandemic we have started an online crystallography school with live lectures and live Q\&A using Zoom Webinar. In 2020 we ran three versions of the school: two 10 one-hour classes on basic topics in crystallography and five 1.5hour classes on advanced topics. In June 2021 we plan to run a fourth school consisting of 101.5 hour classes on advanced topics. We have reported on the execution and results of the two basic schools held in 2020 previously (1).

For the June 2021 school, we have scheduled ten 1.5 hour lectures on advanced topics including: electron diffraction, refinement, twinning, powder and PDF analysis, solution scattering and macromolecular crystallography, non-spherical atom refinement and charge density analysis, and data mining.

This presentation will review the execution and outcomes of the December 2020 and June 2021 advanced topics schools.

1. Ferrara JD, Cochran A, Del Campo M, Göb CR, Le Maguerès P, Meyer M, Puschmann H, Schürmann C, Stanley A, Swepston PN, Tripathi A, White F, Wojciechowski J. Teaching a large-scale crystallography school with Zoom Webinar. Struct Dyn. 2021 Feb 24;8(1):010401.

Keywords: teaching crystallography, pandemic, webinar 